
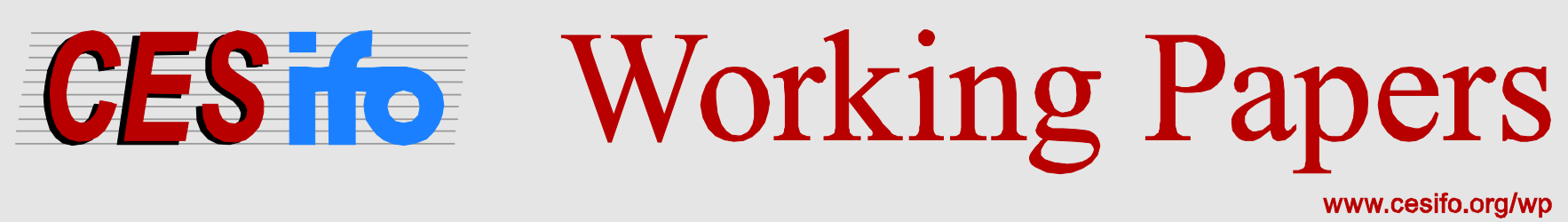

\title{
Bidding for Firms with Unknown Characteristics
}

\author{
Johannes Becker \\ Andrea Schneider
}

CESIFO WORKING PAPER NO. 4806

CATEGORY 1: PuBliC FinANCE

MAY 2014

An electronic version of the paper may be downloaded

- from the SSRN website:

- from the RePEc website:

- from the CESifo website:

WWw.SSRN.com

www.RePEc.org

www.CESifo-group.org/wp

\section{CESifo}




\title{
Bidding for Firms with Unknown Characteristics
}

\begin{abstract}
When a region successfully attracts a large firm by offering tax concessions, outright subsidies etc., the firm often commits itself to performance targets in terms of investment or employment. This paper interprets these contractually fixed targets as a consequence of incomplete information. It analyzes a model of two regions which compete for a large firm assuming that the firm's characteristics are ex-ante unknown. We consider direct mechanisms that induce truthful reporting of the firm's type as well as simpler bidding strategies. We find that, first, performance targets are an equilibrium outcome if information is incomplete. Second, these performance targets often induce employment distortions (overemployment in the most plausible case). Third, when the competing regions differ, the winning region may gain from the fact that information is incomplete, i.e. its payoff is greater than it would be under complete information. Finally, when the governments' sets of instruments are restricted to lump-sum payments, simple tax rebates and wage subsidies, incomplete information has no efficiency cost. This implies that restricting both regions' sets of policy instruments may improve efficiency.
\end{abstract}

JEL-Code: H250, H320, H870.

Keywords: business taxation, state aids, subsidy competition, incomplete information, mechanism design.

\author{
Johannes Becker* \\ Institute of Public Economics \\ University of Münster \\ Wilmergasse 6-8 \\ Germany - 48143 Münster \\ johannes.becker@wiwi.uni-muenster.de
}

\author{
Andrea Schneider \\ Institute of Public Economics \\ University of Münster \\ Wilmergasse 6-8 \\ Germany-48143 Münster \\ andrea.schneider@uni-muenster.de
}

*corresponding author

This version May 7, 2014

We thank Sebastian Krautheim, Grégoire Rota Graziosi, Marco Sahm and participants at conferences in Taormina, Düsseldorf, München and Mannheim for helpful comments. The usual disclaimer applies. 


\section{Introduction}

The location of a large firm in a given jurisdiction can substantially increase its residents' welfare - by increasing employment, wages and tax revenue. Moreover, additional positive effects on the economy may arise in the form of spillovers. It is therefore not surprising that municipal or regional governments are willing to offer tax concessions or outright subsidies to attract large firms. Often these financial incentives are associated with some performance commitment in terms of investment, output or - in most cases employment. These contractually fixed commitments may be interpreted as a consequence of incomplete information: An individual region is willing to bid for the firm according to the surplus it creates - but the size of the surplus may a priori be unknown or, at least, only imprecisely measurable. By committing itself to some performance target, the firm may signal its type and, thus, reduce the information asymmetry. The question arises, though, whether these commitments are generally welfare-enhancing.

In this paper, we consider a model with two regions which engage in a first-price sealed bid auction for a large firm with unknown characteristics. These characteristics will ultimately determine the welfare gain from attracting the firm. Welfare gains take the form of increased tax revenue, reduced unemployment and spillovers on tax revenue from other sources. Whereas the firm's employment is controllable and ex-post verifiable, profits (i.e. the corporate tax base) cannot be controlled due to stochastic shocks, but can be verified ex-post. Spillovers can be neither controlled nor verified. We consider direct non-linear mechanisms that induce truthful reporting of the firm's type as well as simpler bidding strategies, under both symmetric and asymmetric competition.

We find that, first, as with complete information, the symmetric equilibrium under incomplete information generally yields zero expected regional payoffs and full capture of the surplus by each firm type. Second, in equilibrium offers, payments and subsidies to the firm are conditioned on employment levels (performance targets). Third, if spillovers vary with firm type, equilibrium offers generally induce employment distortions. If spillovers are larger for high employment types - which we find most plausible -, the equilibrium contract dictates inefficiently high labor demand for the high employment types. In contrast, if spillovers are lower for high employment firms, there will be underemployment. In the absence of type-dependent spillovers, the bidding outcome has the same efficiency properties as under complete information; specifically, employment of each firm type is at its first-best level. Fourth, in asymmetric settings (i.e. where profits or 
spillovers are location-specific), situations may arise where regional payoffs are larger than in the case of complete information. This is surprising, since the regions are the uninformed parties in this game. Finally, under incomplete information, a limitation of the set of policy instruments may enhance efficiency. Specifically, we show that if regions cannot condition their bids on the firm's performance (e.g. employment) but are restricted to lump-sum payments, simple tax rebates and employment subsidies, the first-best allocation prevails. Since regional payoffs in the symmetric setting are zero in both cases, such a restriction of available instruments would imply a Pareto improvement with the firm capturing the whole increase in payoffs.

There is a large literature on regional competition for the location of firms. ${ }^{2}$ An important question in this literature is why the region wants to attract a firm. In this paper, our answer to this question is tax revenue and jobs - like, for instance, Boadway, Cuff and Marceau (2002) - and spillovers, see e.g. Olsen and Osmundsen (2003). However, we neglect the impact of firm location on competition, see e.g. Haufler and Wooton (1999), consumer surplus, see Becker and Fuest (2010), and agglomeration economies, see e.g. Baldwin and Okubo (2009). We also abstract from any considerations of industry structure. ${ }^{3}$

The focus of this paper is on the role of incomplete information which has been considered by a number of predecessor studies. Bond and Samuelson (1986) assume that the region has more information on the location profitability than the firm. Tax holidays may then act as a signal for the location quality. Private information on the side of the bidding governments is also considered in Furusawa, Hori and Wooton (2010). ${ }^{4}$ King, McAfee and Welling (1993) study the role of incomplete information when firms may relocate and, thus, have an incentive to update their expectations of location-specific profits. Black and Hoyt (1989) briefly consider the case in which the firm has private information on the cost differences between regions. If cost parameters are different across regions, part of the surplus is region specific. This perspective is taken in Scoones and Wen (2001) who show that the degree of bidding competition decreases in the share of region

\footnotetext{
${ }^{2}$ The tax sensitivity of firm location has also been examined in a wide variety of studies which are surveyed by Devereux (2007), Zodrow (2010) and Feld and Heckemeyer (2011).

${ }^{3}$ There is a literature strand of its own dealing with the analysis of heterogeneous firms in the tradition of Melitz (2003) and Helpman, Melitz and Yeaple (2004). Chor (2009), Davies and Eckel (2010), Becker and Fuest (2011) as well as Haufler and Stähler (2013) analyze optimal tax policy in the presence of heterogeneous mobile firms.

${ }^{4} \mathrm{~A}$ simple setting with two-sided private information is analyzed in King and Welling (1992).
} 
specific surplus.

When the set of policy instruments to attract the firm becomes more sophisticated, a region may use direct mechanisms that induce truth-telling about actual profits and employment levels, building on Baron and Myerson (1982). Osmundsen et al. (1998) consider a small country facing a passive world market that sets out to optimally tax firms differing in mobility. They show that, in equilibrium, investment is distorted downwards. In contrast, we consider two actively competing governments, as Olsen and Osmundsen (2001, 2003). These authors adopt a model from Haaparanta (1996) where the firm may invest in both countries (and will do so because of the concavity of local production functions). They analyze tax competition for a firm with private information on its productivity. The screening equilibrium implies a downward distortion of investment.

This common agency approach (see, e.g., Martimort and Stole, 2002, for a general treatment) is different from the perspective taken in this paper. We consider regional competition for the exclusive location of a firm (as in Biglaiser and Mezzetti, 1993). The difference is crucial. In the Olsen and Osmundsen $(2001,2003)$ approach, a region effectively competes for the marginal unit of capital, which often has a net social return of zero. In contrast, by assuming that the firm either locates in this or the other region implies that all tax revenue, all employment and all spillovers is concentrated in the region that wins the bidding competition. This gives rise to Bertrandstyle competition and a race to the bottom. If however, part of the firm always remains in one country, tax rates will never reach the bottom (due to the trade-off between taxing intramarginal units and competing for marginal units). Correspondingly, we find that, in plausible cases, a direct truthinducing mechanism implies overemployment instead of underemployment (the latter of which corresponds to the underinvestment result of Olsen and Osmundsen, 2001, 2003). ${ }^{5}$

From an empirical point of view, there is large and extensive evidence of firm-specific state aids, subsidies or tax holidays, see e.g. Besley and Seabright (2001). Policies to attract foreign firms are anything but homogenous. In some cases, unconditional tax credits seem to be the main policy

\footnotetext{
${ }^{5}$ Bierbrauer et al. (2013) analyze non-linear taxation of individuals with perfect labor mobility. Their framework is similar to ours with regard to two competing governments implementing direct mechanisms to let individual agents reveal their type. They find that, in most cases, redistribution (i.e. taxes and subsidies) do not survive perfect labor mobility - the equivalent finding in our paper is that firms receive the full surplus (at least in the symmetric setting). In contrast to their paper, we assume spillovers that create the incentive to distort the agent's decision (in our paper: employment).
} 
instrument. For instance, in 2010, Michigan won over Ohio by attracting a new Chrysler assembly plant offering the firm a $\$ 1.3$ billion state tax credit over 20 years. ${ }^{6}$ More recently, the rental car service Hertz announced to move its headquarters to Florida in exchange of $\$ 16.8$ million of immediate payments and tax credits worth $\$ 68$ million over 20 years. ${ }^{7}$ In other cases, tax rebates are associated with an incentive to employ domestic workers, as it was the case with Thyssen Krupp in 2007 (and later in 2011) investing in Mobile County (Alabama). ${ }^{8}$ Moreover, governments sometimes fix specific investment and employment targets. For example, Boeing may only receive the full subsidy package with a total value of $\$ 900$ million (offered to it in 2009 to build a new aircraft plant in North Charleston) if some specific investment and jobs targets are met. ${ }^{9}$ Another example is the case of Nokia, from which the State of Northrhine-Westfalia successfully claimed back 40 million $€$ arguing that the firm did not meet the employment targets. ${ }^{10}$ In this paper, we rationalize this kind of contract and, with some interpretation, even the incentive to employ less people than contractually fixed.

The remainder of the paper is organized as follows. The next section outlays the model setup. Section 3 analyzes the bidding competition under symmetry assumptions. Section 4 examines different assumptions about asymmetry between the two competing regions. In Section 5, we analyze less sophisticated bidding strategies in which regional governments only have upfront payments, tax rebates and wage subsidies at their disposal. Section 6 discusses the results and concludes.

\footnotetext{
${ }^{6}$ See Michigan Economic Development Corporation (October 26, 2010). Available at http://www.michiganbusiness.org/press-releases/governor-granholm-announceshistoric-investment-in-michigan/.

${ }^{7}$ See Lynn K., Hugh, R.M. and L. Moss (May 7, 2013). Hertz moving 550 from Park Ridge HQ to Florida. NorthJersey.com. Available at: http://www.northjersey.com/parkridge/206408211_Hertz_moves_from_New_Jersey_to_ Florida.html.

${ }^{8}$ See Jeff Amy (April 28, 2011). Alabama state and local aid to ThyssenKrupp tops $\$ 1$ billion after vote. Mobile Register. Available at http://blog.al.com/live/2011/04/alabama_state_and_local_aid_to.html.

${ }^{9}$ Data are taken from David Slade (January $\left.\overline{17}, \quad 2010\right)$ : Boeing's whopping incentives. The Post and Courier. Available at http://www.postandcourier.com/article/20100117/PC1602/301179958.

${ }^{10}$ See Louven S. and Slodczyk K. (March 11, 2008). Available at http://www.handelsblatt.com/politik/deutschland/subventionszahlungen-nrw-will60-millionen-von-nokia-seite-all/2932968-all.html
} 


\section{Model setup}

Consider a world with two regions, $i=1,2$, competing for a large firm (the index will be suppressed as long as there is no misunderstanding). The firm chooses the location which offers the largest net payoffs (including tax breaks, subsidies, upfront payments etc.). If payoffs are equal in both regions, the large firm is indifferent between both locations and chooses each region with equal probability. Once the firm has chosen the location, it stays there. $^{11}$

The firm is characterized by a parameter $\theta \in\{l, h\}$, which represents low $(l)$ and high $(h)$ productivity and is private information of the firm (and cannot be credibly revealed). The ex-ante probabilities for the firm characteristic are $p_{l}$ for the low-productivity type and $p_{h} \equiv 1-p_{l}$ for the high-productivity type. These probabilities are common knowledge. The firm employs labor, $N$, as the only input good. Its pre-tax profits, $\Pi$, are given by

$$
\Pi(\theta, N)=F_{\theta}(N)-w N+\varepsilon_{\theta}
$$

where $\varepsilon_{\theta} \equiv \varepsilon(\theta)$ is a type-dependent stochastic shock and $F_{\theta}(N) \equiv F(\theta, N)$. Profit maximization requires $\partial F_{\theta}(N) / \partial N=w$. We will denote the profitmaximizing level of a firm with type $\theta$ by $N_{\theta}$ and the respective pre-tax profits by $\Pi_{\theta} \equiv \Pi\left(\theta, N_{\theta}\right)$. We will assume that, at each employment level, the marginal labor productivity is higher for the $h$-type than for the $l$ type, i.e. $\partial F_{h}(N) / \partial N>\partial F_{l}(N) / \partial N$ for all $N$. This implies that, for all environments considered here, profit maximizing employment is strictly higher in an $h$-type firm than in an $l$-type firm. Moreover, we assume that $h$-type has weakly larger maximum profits. ${ }^{12}$

In each of the two regions there is a large number of immobile households, normalized to unity. Each household supplies one unit of labor and receives labor income of $w$. Unemployed households receive a social transfer of $w^{s}$ from the government. Household $k^{\prime}$ s utility function is given by

$$
u\left(c_{k}, I_{k}, g\right)=v\left(c_{k}, I_{k}\right)+g
$$

where $c_{k} \in\left\{w, w^{s}\right\}$ is consumption, $I_{k}$ is a binary variable that is one if the household works and zero if the household does not work but receives social transfers, and $g$ is a public good. Perfect competition on the labor market adjusts wages $w$ until all households have the same utility, $v(w, 1)=$

\footnotetext{
${ }^{11}$ There is no relocation option like in King, McAfee and Welling (1993).

${ }^{12}$ This requires that $F_{h}\left(N_{h}\right)-F_{l}\left(N_{l}\right)>w\left(N_{h}-N_{l}\right)$ for all $w$.
} 
$v\left(w^{s}, 0\right)$, and utility can be denoted by $u(g)$.

The government is assumed to be benevolent. It collects tax revenue, provides the public good and pays the social transfer to all unemployed households. Tax revenue from other sources is given by $R$. Let $R_{0}$ denote the level of these revenues if the firm is not attracted.

The firm location may have spillovers which depend, by assumption, on the firm type, but not directly on the level of employment. For simplicity, we assume that spillovers only affect the government's revenues from other sources. Thus, these revenues are $R_{\theta}$ after location of a firm of type $\theta$, where $R_{\theta} \gtreqless R_{0}$ and $R_{l} \gtreqless R_{h}$.

We assume that tax revenue can be transformed into the public good on a one-to-one basis. Then, the government's budget constraint in the absence of the large firm is given by

$$
g_{0} \equiv R_{0}-w^{s}(1-n)
$$

If the large firm is attracted and realizes an employment level $N_{\theta}$, the government's budget constraint becomes

$$
g_{\theta}=R_{\theta}+t \Pi_{\theta}\left(N_{\theta}\right)-w^{s}\left(1-n-N_{\theta}\right)-T_{\theta}
$$

where $t$ is the statutory regional corporate tax rate and $T_{\theta}$ is the upfront payment to the firm of type $\theta$. Thus, if $T_{\theta}=0$, the regional payoff from attracting the firm is given by

$$
g_{\theta}-g_{0}=w^{s} N_{\theta}+t \Pi_{\theta}\left(N_{\theta}\right)+R_{\theta}-R_{0}
$$

where the right hand side represents the maximum level of $T_{\theta}$ that the region is willing to offer. There are, thus, three reasons why a region desires to attract the firm. First, a reduction in unemployment, which here means saving of unemployment benefits (first term on the right hand side in (5)). The firm's employment level can directly be controlled by the firm and it can be verified ex-post. Second, tax revenue, i.e. a share of the firm's profits (second term). Profits cannot be directly controlled, as they are stochastic, but may be verified ex-post. Third, the spillover, $R_{\theta}-R_{0}$, which can neither be controlled nor be verified ex-post (third term). As the following analysis will show, none of these three elements is redundant.

In the absence of any policy intervention, the firm sets the profit-maximizing level of employment, implied by $\frac{\partial F_{\theta}\left(N_{\theta}\right)}{\partial N_{\theta}}=w$. Since an additional unit of employment saves the region expenditures on unemployment benefits, the socially optimal employment level is larger than that. It is straightfor- 
ward to show that first-best employment implies $\frac{\partial F_{\theta}\left(N_{\theta}\right)}{\partial N_{\theta}}=w-w^{s}{ }^{13}$ Let $N_{\theta}^{*}$ denote the socially optimal employment level and $\Pi_{\theta}^{*} \equiv \Pi\left(\theta, N_{\theta}^{*}\right)$ the respective profits for a firm of type $\theta$.

The timing of the model is as follows: First, a first price sealed bid auction takes place in which both regions simultaneously submit their offers for the firm. Second, the firm decides where to locate and chooses its labor demand. Finally, governments' revenues and firms' profits are realized.

\section{Symmetric bidding competition}

In this section, we consider regional competition for a firm between two identical regions. That is, both regions have the same tax rates, same unemployed transfers $w^{s}$ and so on. Asymmetries are considered in section 4 .

In the following, we will consider three direct mechanisms. The first one, in subsection 3.1, assumes that profits cannot be contracted upon. This means that the contract between the region and the firm takes the form of an employment target (which has to be met by the firm) and an upfront lump-sum payment. The region, thus, does not make use of the fact that profits can be verified ex-post.

The second mechanism, in subsection 3.2, allows for tax rebates which can be interpreted as a simple way of conditioning payments on profits. That is, for a given tax rate, the more profits the firm has, the higher the value of the tax rebate. We do believe that this is the most plausible setting as we actually observe contracts that include this kind of simple profit conditions, but not more sophisticated ones.

For the sake of analytical completeness, we consider a third mechanism in subsection 3.3 in which we allow for sophisticated conditions based upon profits. We are not aware that this kind of contract exists in the real world, although - as we will show - it has powerful advantages. ${ }^{14}$

\footnotetext{
${ }^{13}$ To see this, assume that the government may set $N_{\theta}$ while adjusting $T_{\theta}$ such that $(1-t) \Pi_{\theta}+T_{\theta}$ stays constant which requires $d T_{\theta}=-(1-t)\left[\frac{\partial F_{\theta}\left(N_{\theta}\right)}{\partial N_{\theta}}-w\right] d N_{\theta}$. Then, $g_{\theta}-$ and, thus, $u\left(g_{\theta}\right)-$ is maximized at $\frac{d g_{\theta}}{d N_{\theta}}=\frac{\partial F_{\theta}\left(N_{\theta}\right)}{\partial N_{\theta}}-\left(w-w^{s}\right)=0$.

${ }^{14}$ Of course, this raises the question, why profits are not conditioned upon in the real world. Note that simple volatility due to stochastic shocks would not be a sufficient reason since this should not be a problem for risk-neutral firms and governments. It may, however, be that profits are received with varying time lags which makes contracting upon them undesirable. We defer this question to later research.
} 


\subsection{A direct mechanism conditioning on employment}

Assume that profits and spillovers cannot be contracted upon. A direct mechanism ${ }^{15}$ conditioning on employment means that the region may offer a menu of contracts taking the form of $(\hat{N}, \hat{T})$ where $\hat{N}$ denotes the employment level that leads to a payment of $\hat{T}$. Equivalently, the region may ask the firm to reveal its type and then assigns a contract $\left(\hat{N}_{\tilde{\theta}}, \hat{T}_{\tilde{\theta}}\right)$ where $\hat{N}_{\tilde{\theta}}$ and $\hat{T}_{\tilde{\theta}}$ denote the employment level and the payment in case of a report of type $\theta(\tilde{\theta}$ denotes the reported type).

Truthful revelation of the firm type requires that the $h$-type has no incentive to mimick the $l$-type and vice versa. These requirements are summarized in the two following incentive compatibility constraints $\left(I C C_{h}\right)$ and $\left(I C C_{l}\right)$ :

$$
\begin{array}{rr}
(1-t)\left(F_{h}\left(\hat{N}_{h}\right)-w \hat{N}_{h}\right)+\hat{T}_{h} \geq(1-t)\left(F_{h}\left(\hat{N}_{l}\right)-w \hat{N}_{l}\right)+\hat{T}_{l} & \left(I C C_{h}\right) \\
(1-t)\left(F_{l}\left(\hat{N}_{l}\right)-w \hat{N}_{l}\right)+\hat{T}_{l} \geq(1-t)\left(F_{l}\left(\hat{N}_{h}\right)-w \hat{N}_{h}\right)+\hat{T}_{h} & \left(I C C_{l}\right)
\end{array}
$$

We can now state the following Lemma.

Lemma 1. In any truth-telling symmetric (pure-strategy) bidding equilibrium (i) the employment level offered to the h-type is at least as high as the level offered to the l-type, $\hat{N}_{h} \geq \hat{N}_{l}$, (ii) both regions are indifferent between attracting the firm and not, and (iii) each type of firm gets its full surplus.

Proof: (i) Adding $\left(I C C_{h}\right)$ and $\left(I C C_{l}\right)$ implies $F_{h}\left(\hat{N}_{h}\right)-F_{l}\left(\hat{N}_{h}\right) \geq$ $F_{h}\left(\hat{N}_{l}\right)-F_{l}\left(\hat{N}_{l}\right)$. Since, by above assumption, $F_{h}(N)-F_{l}(N)$ strictly increases in $N$, incentive compatibility requires $\hat{N}_{h} \geq \hat{N}_{l}$. (ii) If the regions' bids imply positive expected payoffs from attracting the firm, a region can attract all types of firms with certainty by increasing its bids by $\varepsilon$. (iii) Part (ii) implies that, if one firm type receives less than the full surplus, the other type receives more than that. Then, a region can increase its expected payoffs by offering only the contract that yields positive profits. Thus, a separating contract with cross-subsidization cannot be an equilibrium offer. It remains to show that there is no pooling equilibrium. First note that a pooling offer with an employment level below $N_{l}^{*}$ or above $N_{h}^{*}$ is not sustainable. A pooling offer with employment between $N_{l}^{*}$ or above $N_{h}^{*}$ means that at least one type's employment is distorted. A region can now offer a contract with an employment level closer to one firm's desired level of employment while adjusting the payment $T_{\tilde{\theta}}$ such that this type stays

\footnotetext{
${ }^{15}$ This approach builds on the Baron and Myerson (1982) model.
} 
indifferent. Since the other firm type's employment would be distorted even more, it would always prefer the other region's pooling offer. Thus, a region can always make a profitable deviation from a pooling offer. It can therefore not be an equilibrium.

Proposition 1 summarizes the characteristics of the symmetric separating equilibrium in pure strategies, given Lemma 1.

Proposition 1 (Conditioning on employment). Let $\underline{\Delta R}$ and $\overline{\Delta R}$ denote two thresholds for the difference in spillovers, $R_{h}-R_{l}$.

(i) If $\underline{\Delta R} \leq R_{h}-R_{l} \leq \overline{\Delta R}$, any symmetric separating equilibrium in pure strategies requires efficient emplyoment levels for both types, i.e. $\hat{N}_{l}=N_{l}^{*}$ and $\hat{N}_{h}=N_{h}^{*}$.

(ii) If $R_{h}-R_{l}>\overline{\Delta R}$, any symmetric separating equilibrium in pure strategies requires $\hat{N}_{l}=N_{l}^{*}$ and $\hat{N}_{h}>N_{h}^{*}$ (overemployment).

(iii) If $R_{h}-R_{l}<\Delta R$, any symmetric separating equilibrium in pure strategies requires $\hat{N}_{h}=N_{h}^{*}$ and $\hat{N}_{l}<N_{l}^{*}$ (underemployment).

Proof: With efficient employment levels, i.e. $\hat{N}_{h}=N_{h}^{*}$ and $\hat{N}_{l}=N_{l}^{*}$, and full surplus capture by the two firm types, $\left(I C C_{h}\right)$ and $\left(I C C_{l}\right)$ hold if $R_{h}-R_{l} \geq \Delta R$ and $R_{h}-R_{l} \leq \overline{\Delta R}$ with

$$
\begin{aligned}
\underline{\Delta R} & \equiv F_{h}\left(N_{l}^{*}\right)-\left(w-w^{s}\right) N_{l}^{*}-\left[F_{h}\left(N_{h}^{*}\right)-\left(w-w^{s}\right) N_{h}^{*}\right]+t\left(F_{l}\left(N_{l}^{*}\right)-F_{h}\left(N_{l}^{*}\right)\right)(6) \\
\overline{\Delta R} & \equiv F_{l}\left(N_{l}^{*}\right)-\left(w-w^{s}\right) N_{l}^{*}-\left[F_{l}\left(N_{h}^{*}\right)-\left(w-w^{s}\right) N_{h}^{*}\right]-t\left(F_{h}\left(N_{h}^{*}\right)-F_{l}\left(N_{h}^{*}\right)\right)(7)
\end{aligned}
$$

(i) With $\overline{\Delta R}>\Delta R$, it follows that if $\underline{\Delta R} \leq R_{h}-R_{l} \leq \overline{\Delta R}$, there is a symmetric equilibrium with efficient employment. (ii) If $R_{h}-R_{l}>\overline{\Delta R}$, $\left(I C C_{l}\right)$ is violated at efficient employment levels, whereas $\left(I C C_{h}\right)$ is not binding. As the right hand side of (7) increases in $\hat{N}_{h}$, it is optimal to set the efficient employment level for the $l$-type and increase $\hat{N}_{h}$ beyond the efficient level. (iii) If $R_{h}-R_{l}<\underline{\Delta R}$, the $\left(I C C_{h}\right)$ is violated at efficient employment levels. It is now optimal to reduce $\hat{N}_{l}$ such that $\hat{N}_{l}<N_{l}^{*}$ while keeping $\hat{N}_{h}$ at its efficient level, $\hat{N}_{h}=N_{h}^{*}$.

The contracts described in Proposition 1 can be implemented in the following way: All firms get an employment subsidy of $\omega\left(\hat{N}_{\tilde{\theta}}\right)$ which is a function of employment. If $\underline{\Delta R} \leq R_{h}-R_{l} \leq \overline{\Delta R}$, the slope of this subsidy function equals $w^{s}$ in the vicinity of $N_{l}^{*}$ and $N_{h}^{*}$. If $R_{h}-R_{l}>\overline{\Delta R}$, the slope of the function is greater as $w^{s}$ in the vicinity of $\hat{N}_{h}>N_{h}^{*}$. Finally, if $R_{h}-R_{l}<\underline{\Delta R}$, the slope equals $w^{s}$ in the vicinity of $N_{h}^{*}$ and is lower 
then $w^{s}$ around $\hat{N}_{l}<N_{l}^{*}$. Moreover, total subsidy payments should equal $R_{\theta}-R_{0}+t \Pi_{\theta}\left(\hat{N}_{\theta}\right)+w^{s} \hat{N}_{\theta}$ with $\theta \in\{l, h\}$.

Proposition 1 characterizes a symmetric separating equilibrium for different environments - in case that it exists. There may be, however, situations in which an equilibrium in pure strategies does not exist, like in the insurance markets model by Rothschild and Stiglitz (1976). To see this, consider a situation in which both types are offered a contract which makes them capture the full surplus. However, due to distorted labor demand, a deviation is feasible that offers the distorted type a more efficient labor demand while making sure (by reducing $\hat{T}_{\theta}$ ) that the non-distorted firm type's ICC holds with equality.

Proposition 2 defines conditions for the existence of these equilibria.

Proposition 2. (i) If $\underline{\Delta R} \leq R_{h}-R_{l} \leq \overline{\Delta R}$, a symmetric separating equilibrium always exists.

(ii) If $R_{h}-R_{l}>\overline{\Delta R}$, a symmetric separating equilibrium exists if $p_{h}$ is sufficiently small.

(iii) If $R_{h}-R_{l}<\underline{\Delta R}$, a symmetric separating equilibrium exists if $p_{l}$ is sufficiently small.

Proof: (i) If $\underline{\Delta R} \leq R_{h}-R_{l} \leq \overline{\Delta R}$, both types' employment levels are efficient, and both types capture the full surplus. Since this is the first-best, a profitable deviation is not feasible. (ii) Assume a situation in which the region offers a contract $\left(N_{l}^{*}, T_{l}^{*}\right)$ and some contract $\left(\hat{N}_{h}, \hat{T}_{h}\right)$. The latter ensures that the $\left(I C C_{l}\right)$ holds with equality, but it may yield non-zero expected profits for the region, denoted by $X \equiv$ $p_{h}\left(t \Pi_{h}\left(\hat{N}_{h}\right)+w^{s} \hat{N}_{h}+R_{h}-R_{0}-\hat{T}_{h}\right)$. By increasing both bids by $X$, the zero profit condition is restored. For the $\left(I C C_{l}\right)$ to hold with equality, a variation of $\hat{N}_{h}$ and $\hat{T}_{h}$ must satisfy

$$
(1-t)\left(F_{l}^{\prime}\left(\hat{N}_{h}\right)-w\right) d \hat{N}_{h}+d \hat{T}_{h}=0
$$

Starting with $\hat{N}_{h}=N_{h}^{*}$, a small increase in $\hat{N}_{h}$ (and an increase in $\hat{T}_{h}$ according to (8)) increases the firm's profits if $p_{h}\left(F_{l}^{\prime}\left(N_{h}^{*}\right)-\left(w-w^{s}\right)\right)+$ $F_{h}^{\prime}\left(N_{h}^{*}\right)-F_{l}^{\prime}\left(N_{h}^{*}\right)>0$ (if not, then there is no equilibrium in pure strategies as Lemma 1 is violated). If $\hat{N}_{h}$ is further increased, $X$ will eventually become zero. If this happens in a range where the $h$-type's profits still increase in $\hat{N}_{h}$, then this is an equilibrium. However, if the $h$-type's profits reach a 
maximum before the region's profits are zero, then no equilibrium in pure strategies exists (as Lemma 1 is violated). The firm's profits are maximized at $\hat{N}_{h}^{\prime}$ implied by $p_{h}\left(F_{l}^{\prime}\left(\hat{N}_{h}^{\prime}\right)-\left(w-w^{s}\right)\right)+F_{h}^{\prime}\left(\hat{N}_{h}^{\prime}\right)-F_{l}^{\prime}\left(\hat{N}_{h}^{\prime}\right)=0$. It is straightforward to show that, since $F_{h}^{\prime}\left(\hat{N}_{h}^{\prime}\right)-F_{l}^{\prime}\left(\hat{N}_{h}^{\prime}\right)>0, \hat{N}_{h}^{\prime}$ decreases in $p_{h}$. In contrast, the level of $\hat{N}_{h}$ which makes $X$ become zero does not depend on $p_{h}$. This proves part (ii) of the Proposition. (iii) The proof is equivalent to the one in (ii).

Proposition 2 part (ii) is in line with Rothschild and Stiglitz (1976). If the probability of being an $l$-type is too low, separating becomes too expensive for the $h$-type. In this case, there is a pooling contract (but not an equilibrium) in which both types are better off than in the equilibrium described in Proposition 1 part (ii), and the region offering such a contract earns positive revenues. Dasgupta and Maskin (1986) prove for the Rothschild-Stiglitz model the existence of an equilibrium in mixed strategies where the result is directly applicable here. The symmetric equilibrium in mixed strategies has the same properties as the equilibrium in pure strategies. The government realizes zero expected profits, there is overemployment if $R_{h}-R_{l}>\overline{\Delta R}$ and underemployment if $R_{h}-R_{l}<\underline{\Delta R}$. Other approaches of dealing with the non-existence of equilibrium in a Rothschild-Stiglitz framework can be found in Wilson (1977) and Riley (1979). Wilson (1977) introduces the concept of an anticipatory equilibrium in which governments are allowed to withdraw contracts when they realize that these contracts imply negative revenues (given the other government's bid). Applied to the framework here, if the equilibrium in Proposition 1 does not exist, the anticipatory equilibrium pools both types of firms and implies zero-profits for the governments. If the equilibrium in Proposition 1 exists, it is also a Wilson equilibrium. In contrast, the concept of a reactive equilibrium by Riley (1979) allows the governments to react to unprofitable situations by adding new contracts. With this equilibrium concept the separating equilibrium described in Proposition 1 exists independently of the ex-ante fractions of both types of firms. In general, if a Rothschild-Stiglitz equilibrium does not exist, an equilibrium can only be ensured by extending the governments' scope of action and, therefore, by changing the structure of the game. The characteristics of the equilibrium bidding contracts then depend on the specific equilibrium concept underlying the analysis. In the following, we will assume that an equilibriumn exists. 


\subsection{A direct mechanism conditioning on employment with simple tax rebates}

The analysis in the previous subsection and the results in Proposition 1 do not take into account that the region can make use of the fact that profits are verifiable ex-post. Why should that be important? Risk-neutral firms can be assumed to be indifferent between receiving ex-post their actual tax payments (this is what a tax rebate is) or receiving ex-ante the expected tax payments.

However, the choice between refunding actual or expected tax payments may affect the incentive compatibility constraints. On the one hand, the offer of expected tax payments of the $h$-type is more attractive to the $l$ type than an actual tax rebate (since $l$-type profits are lower in expected terms). On the other hand, offering expected tax payments of the l-type is less attractive to the $h$-type than actual tax rebates. Thus, if the $\left(I C C_{l}\right)$ for the low-productivity type is binding, the regions will offer actual tax payments. If the $\left(I C C_{h}\right)$ is binding, offering repayment of expected tax payment relaxes the constraint compared to actual tax payments.

We can therefore state the following Proposition.

Proposition 3 (conditioning on employment with ex-post verifiable profits). Assume that profits are verifiable ex-post. Then, Prop. 1 applies with $\overline{\Delta R}^{\prime}$ instead of $\overline{\Delta R}$, with $\overline{\Delta R}^{\prime}>\overline{\Delta R}$. Offering rebates instead of upfront repayment of expected tax payments increases efficiency. All efficiency gains are captured by the h-type firm.

Proof: With refunding of actual tax payments, $\left(I C C_{l}\right)$ reads $F_{l}\left(N_{l}^{*}\right)$ $w N_{l}^{*}+w^{s} N_{l}^{*}+R_{l} \geq F_{l}\left(N_{h}^{*}\right)-w N_{h}^{*}+w^{s} N_{h}^{*}+R_{h}$, and the modified version of $(7)$

$$
\overline{\Delta R}^{\prime} \equiv F_{l}\left(N_{l}^{*}\right)-\left(w-w^{s}\right) N_{l}^{*}-\left[F_{l}\left(N_{h}^{*}\right)-\left(w-w^{s}\right) N_{h}^{*}\right]>0
$$

With $\overline{\Delta R}^{\prime}>\overline{\Delta R}$, the range in which first-best employment levels are offered is broadened. With Lemma 1 , it follows that the resulting efficiency gains are completely captured by the $h$-type firm (the $l$-type firm is nondistorted anyway).

With $\overline{\Delta R}^{\prime}>0$ and $\underline{\Delta R}<0$, we can now state the following Corollary.

Corollary 1. With $R_{h}-R_{l}=0$, i.e. no or no type-dependent spillovers, offers imply first-best employment. 
The contracts described in Proposition 1 can be implemented as described in the previous section with the exception of when $R_{h}-R_{l}>\overline{\Delta R}$. Then, all firms are exempted from corporate taxation and get an employment subsidy of $\omega\left(\hat{N}_{\tilde{\theta}}\right)$ which is a function of employment. The slope of this subsidy function equals $w^{s}$ in the vicinity of $N_{l}^{*}$ and is greater as $w^{s}$ in the vicinity of $\hat{N}_{h}>N_{h}^{*}$. Moreover, total subsidy payments should equal $R_{\theta}-R_{0}+w^{s} \hat{N}_{\theta}$ for $\theta \in\{l, h\}$.

\subsection{A direct mechanism conditioning on employment and profits}

Now, we consider a mechanism that allows for non-linear conditioning on profits. For this purpose, we assume that profits cannot be exaggerated, i.e. the realized maximum profit is $\Pi_{\theta}$, but easily reduced (just by not selling part of the product). Let $\tilde{\Pi}_{\theta} \in\left[-\infty, \Pi_{\theta}\right]$ denote the feasible profit levels of a firm of type $\theta$. Note that expected profits cannot be verified, only actual profits can. Therefore, a mechanism can only condition on realized profits, $\tilde{\Pi}_{\theta}$. Since actual profits may exceed expected profits, an $l$-type firm may have the incentive to speculate on higher actual profits which signal an $h$ type firm. By offering type-dependent payment functions, $\hat{T}_{\tilde{\theta}}\left(\hat{N}_{\tilde{\theta}}, \tilde{\Pi}\right)$, that condition on actual profits $\tilde{\Pi}$, a region may set the incentive to truthfully report the firm type. Let $\hat{T}_{\tilde{\theta}}\left(\hat{N}_{\tilde{\theta}}, \tilde{\Pi}_{\theta}\right)$ denote the payment to a firm that has reported to be type $\tilde{\theta}$ and has actual profits of $\tilde{\Pi}_{\theta}$.

For the firm to truthfully report its actual profits, the payment fucntion $\hat{T}_{\tilde{\theta}}\left(\hat{N}_{\tilde{\theta}}, \tilde{\Pi}\right)$ has to satisfy the property

$$
\frac{\partial \hat{T}_{\tilde{\theta}}\left(\hat{N}_{\tilde{\theta}}, \tilde{\Pi}_{\theta}\right)}{\partial \tilde{\Pi}_{\theta}} \geq-(1-t),
$$

i.e. the payment function can at most eliminate the impact of actual profits on the firm's payoff. The incentive compatibility constraints are given by

$$
(1-t) \Pi_{h}^{e}\left(\hat{N}_{h}\right)+\hat{T}_{h}^{e}\left(\hat{N}_{h}, \tilde{\Pi}_{h}\right) \geq(1-t) \Pi_{h}^{e}\left(\hat{N}_{l}\right)+\hat{T}_{l}^{e}\left(\hat{N}_{l}, \tilde{\Pi}_{h}\right) \quad\left(I C C_{h}^{\prime}\right)
$$

and

$$
(1-t) \Pi_{l}^{e}\left(\hat{N}_{l}\right)+\hat{T}_{l}^{e}\left(\hat{N}_{l}, \tilde{\Pi}_{l}\right) \geq(1-t) \Pi_{l}^{e}\left(\hat{N}_{h}\right)+\hat{T}_{h}^{e}\left(\hat{N}_{h}, \tilde{\Pi}_{l}\right), \quad\left(I C C_{l}^{\prime}\right)
$$


where $\Pi_{\theta}^{e}\left(\hat{N}_{\tilde{\theta}}\right)$ denotes the expected profit of a firm with type $\theta$ reporting type $\tilde{\theta}$ and $\hat{T}_{\tilde{\theta}}^{e}\left(\hat{N}_{\tilde{\theta}}, \tilde{\Pi}_{\theta}\right)$ denotes the respective payment.

We can now state the following Proposition.

Proposition 4 (Conditioning on profits). Let $\underline{\Delta R^{\prime}}<0$ denote a threshold for the difference in spillovers, $R_{h}-R_{l}$. With conditioning on employment and profits, a fully separating equilibrium where both firm types receive their full surplus and employment is at its first-best level is feasible if $R_{h}-R_{l}>$ $\Delta R^{\prime}$. Otherwise, the region's government optimally offers contracts that condition only on employment and Proposition 1 applies.

Proof: First, as before, if $\left(I C C_{h}^{\prime}\right)$ and $\left(I C C_{l}^{\prime}\right)$ hold at efficient employment levels, then the first-best equilibrium can be attained. Second, if only $\left(I C C_{l}^{\prime}\right)$ is binding, then governments set $\hat{N}_{h}=N_{h}^{*}$ since there is no need to distort labor demand. The reason is that additional payments to the $h$ type can now be conditioned upon large profits that cannot be mimicked by the l-type. Third, if $\left(I C C_{h}^{\prime}\right)$ is the binding constraint, the region's government has to account for an additional constraint, since the high-productive type can understate its profits. This puts some bounds on the payment functions $\hat{T}_{h}^{e}\left(\hat{N}_{h}, \tilde{\Pi}_{h}\right)$ and $\hat{T}_{l}^{e}\left(\hat{N}_{l}, \tilde{\Pi}_{h}\right)$. More precisely, the $\left(I C C_{h}^{\prime}\right)$ implies $\hat{T}_{h}^{e}\left(N_{h}^{*}, \tilde{\Pi}_{h}\right)-\hat{T}_{l}^{e}\left(\hat{N}_{l}, \tilde{\Pi}_{h}\right) \geq-(1-t)\left(\Pi_{h}^{e}\left(N_{h}^{*}\right)-\Pi_{h}^{e}\left(\hat{N}_{l}\right)\right)$ which is the discrete version of $(9)$ in expected terms. Replacing $\hat{T}_{h}^{e}\left(N_{h}^{*}, \tilde{\Pi}_{h}\right)$ by $\hat{T}_{h}^{*}$ and $\hat{T}_{l}^{e}\left(N_{l}^{*}, \tilde{\Pi}_{h}\right)$ by $\hat{T}_{l}^{*},\left(I C C_{h}^{\prime}\right)$ holds if

$$
R_{h}-R_{l} \geq-\Pi_{h}^{e}\left(N_{h}^{*}\right)+\Pi_{h}^{e}\left(N_{l}^{*}\right)-w^{s}\left(N_{h}^{*}-N_{l}^{*}\right) \equiv \underline{\Delta R^{\prime}} .
$$

For $R_{h}-R_{l}<\Delta R^{\prime}$, conditioning on profits is useless because the $h$-type can easily mimick the profit levels of the $l$-type.

The above Proposition implies that conditioning on profits would eliminate the case of overemployment. To understand this, it is helpful to recall why there might be overemployment in the case where only employment can be conditioned upon. This case occurs if the $h$-type has larger spillovers than the $l$-type. Since spillovers imply a certain willingness to pay, this means that the region is ready to offer more for the $h$-type. Since a more attractive offer is prone to mimicking, the labor demand is distorted in order to push back the $l$-types pretending to be $h$-types. If profits can be conditioned upon, there is no need to distort employment. By 'subsidizing' profits, the $h$-type offer is improved without changing behavior (firms maximize profits anyway). 
With regard to implementation, a crucial difference compared to the previous subsections only occurs for $R_{h}-R_{l}>\overline{\Delta R}$. Then, firms could get an employment subsidy of $w^{s}$. In addition, a negative tax is paid such that the expected payment to the firm equals $R_{\theta}-R_{0}+t \Pi_{\theta}\left(N_{\theta}^{*}\right)$ with $\theta \in\{l, h\}$.

\section{Asymmetric bidding competition}

So far we considered perfectly symmetric competition. Now, we allow for asymmetries, i.e. differences between the countries that may affect the properties of the bidding equilibrium. For simplicity reasons, we will only focus on the case of $R_{h} \geq R_{l}$, i.e. where spillovers are equal across types or the high-productivity firm has higher spillovers. Results for $R_{h}<R_{l}$ can be derived analogously.

\subsection{Location-specific profit}

The first type of asymmetry we consider here concerns location-specific profits. In section 3, we assumed that, in the absence of regional bids, the firm is indifferent between the regions. In the real world, this will rarely be the case. Now, we consider the case in which the firm has a higher profit in region 1 and would, thus, prefer region 1 in the absence of a bidding competition. The pre-tax profit difference is assumed to equal $\Delta_{\Pi}(\theta)$ which may depend on $\theta, \Delta_{\Pi}(h) \lessgtr \Delta_{\Pi}(l)$. Each of the following results does not depend on whether simple tax rebates are available (as in subsection 3.2) or not (subsection 3.1).

Proposition 5. Assume that the firm's pre-tax profit is larger in region 1 and $R_{h} \geq R_{l}$. Region 2 makes the offer described in Propositions 1 and 3. With $\epsilon$ denoting a small payment, region 1 's $\hat{T}_{l}$ is reduced by $\Delta_{\Pi}(l)-\epsilon$, thus attracting type $l$ with certainty. In comparison to the offer described in Propositions 1 and 3, region 1 changes the offer to type $h$ as follows:

(i) If $\Delta_{\Pi}(h)=\Delta_{\Pi}(l)$, employment distortions remain stable but $\hat{T}_{h}$ is reduced by $\Delta_{\Pi}(\theta)-\epsilon$.

(ii) If $\Delta_{\Pi}(h)>\Delta_{\Pi}(l)$, employment distortions are mitigated and $\hat{T}_{h}$ is reduced by more than $\Delta_{\Pi}(h)-\epsilon$.

(iii) If $\Delta_{\Pi}(h)<\Delta_{\Pi}(l)$, employment distortions are aggravated and $\hat{T}_{h}$ is reduced by less than $\Delta_{\Pi}(h)-\epsilon$.

Proof: (i) If $\Delta_{\Pi}(h)=\Delta_{\Pi}(l)$, the ICCs are not affected. Reducing the offer by $\Delta_{\Pi}(\theta)$ makes the firm indifferent, adding an $\epsilon$ provides a sufficient 
incentive to choose region 1 . (ii) With $\Delta_{\Pi}(h)>\Delta_{\Pi}(l)$, the offer to the $h$-type can be reduced more than to the $l$-type. This relaxes the $I C C_{l}$. This allows region 1 to reduce the labor demand distortion in the offer to the $h$-type. The resulting efficiency gain is captured by the region. (iii) Analogously, $\Delta_{\Pi}(h)<\Delta_{\Pi}(l)$ makes the $I C C_{l}$ more restrictive which requires further distortions of the $h$-type's labor demand. To make the $h$-type choose region 1 , the offer has to be reduced by less than $\Delta_{\Pi}(h)-\epsilon$.

Part (ii) of the above Proposition describes a case in which the region can benefit by more than the total value of the location-specific profit. Compared to the case of complete information, the region gains from the incompleteness of information. The reason is that region 1 competes with a region that offers an employment-distorting contract. In this regard, competition is weaker under incomplete information.

An example of a location-specific profit may be the case in which region 1 has lower wages due to a lower disutility of work. For the sake of the argument, assume that unemployment benefits are equal in both regions, $w_{1}^{s}=w_{2}^{s}$; then, a lower disutility of work implies $w_{1}<w_{2}$. In fact, labor cost is in the centre focus of the debate on multinational firms' location choices. From the viewpoint of the firm, lower labor costs are only important if they translate into higher profits. The gain from lower wages will depend on the size of emplyoment and, thus, on the firm type $\theta$. We can therefore state the following.

Corollary 2. Assume that $w_{1}^{s}=w_{2}^{s}$ and $w_{1}<w_{2}$. Then, the firm has a higher profit in region 1 which depends on $\theta$ and can be expressed as $\Delta_{\Pi}(\theta)$. Proposition 5 applies.

Whether $\Delta_{\Pi}(\theta)$ depends positively or negatively on $\theta$ in this case depends on the shape of the production function $F(\cdot)$.

\subsection{Location-specific spillover}

Now assume that the spillover is location-specific and depends on the firm type $\theta$. Let $\Delta_{R}(\theta)$ denote the location-specific spillover. Location-specific spillovers may, for instance, be explained by a location-specific industry structure. From the viewpoint of region 1, an additional positive spillover does not need to change the bidding strategy since the region only needs to match the offer by region 2. However, if the additional spillover is negative, the maximum offer by region 1 is reduced. Accordingly the whole equilibrium changes. Each of the following results does not depend on whether 
simple tax rebates are available (as in subsection 3.2) or not (subsection $3.1)$.

Proposition 6. Assume that spillovers from firm location are different in region 1 and $R_{h} \geq R_{l}$. If $\Delta_{R}(\theta)>0$, the contracts offered are those described in Propositions 1 and 3, but region 1 may attract the firm with certainty by increasing the lump-sum payments by a small payment $\epsilon$. If $\Delta_{R}(\theta)<0$, region 1's $\hat{T}_{l}$ is reduced by $\Delta_{R}(l)$. Region 1's offer to type $h$ is changed as follows:

(i) If $\Delta_{R}(h)=\Delta_{R}(l)$, employment distortions remain stable but $\hat{T}_{h}$ is reduced by $\Delta_{R}(h)$.

(ii) If $\Delta_{R}(h)<\Delta_{R}$ (l) (but still $R_{h}+\Delta_{R}(h)-R_{l}-\Delta_{R}(l) \geq 0$ ), employment distortions are mitigated and $\hat{T}_{h}$ is reduced by at most $-\Delta_{R}(h)$. The efficiency gain is entirely captured by the h-type firm (i.e. its payoffs decrease by less than $-\Delta_{R}(h)$ ).

(iii) If $\Delta_{R}(h)>\Delta_{R}(l)$, employment distortions are aggravated and $\hat{T}_{h}$ is reduced by at least $-\Delta_{R}(h)$. The efficiency loss is entirely born by the $h$-type firm (i.e. its payoffs decrease by more than $-\Delta_{R}(h)$ ).

Region 2 matches the offer adding $\epsilon$ and attracts the firm with certainty.

Proof: With $\Delta_{R}(\theta)>0$, region 1 has a higher willingness to pay for the firm and may therefore attract the firm by slightly increasing its offers, compared to the case described in Propositions 1 and 3. With $\Delta_{R}(\theta)<0$, region 1 has to reduce its offers (otherwise it could increase payoffs by not bidding at all). (i) If $\Delta_{R}(h)=\Delta_{R}(l)$, payments accounting for locationspecific spillovers do not affect the $I C C$ s. However, to avoid losses region 1 has to decrease its payments by $\Delta_{R}(\theta)$. Region 2 can attract the firms by bidding slightly more than region 1 does. (ii) With $\Delta_{R}(h)<\Delta_{R}(l)$, the $I C C_{l}$ with region 1's maximum bids is relaxed, i.e. implies no or smaller labor demand distortions. With region 1 bidding the full surplus and region 2 matching the offer (adding only $\epsilon$ ), the resulting efficiency gain is captured by the firm. (iii) With $\Delta_{R}(h)>\Delta_{R}(l)$, the $I C C_{l}$ with region 1's maximum bids tightens which implies larger labor market distortion (provided that $I C C_{l}$ has been binding with $\Delta_{R}(\theta)=0$, otherwise labor demand may still be undistorted). Again, with region 1 bidding the (now smaller) surplus and region 2 matching the offer, the resulting efficiency loss is born by the firm.

An example for a location-specific spillover is when the workers in region 1 have a lower disutility of work, but wages are equal in both countries, 
i.e. $w_{1}^{s}>w_{2}^{s}$ and $w_{1}=w_{2}$. Then, attracting the firm in region 1 implies higher savings of unemployment benefits than in region 2 .

Corollary 3. Assume that $w_{1}^{s}>w_{2}^{s}$ and $w_{1}=w_{2}$. Then, the location specific spillover in region 1 equals $\left(w_{1}^{s}-w_{2}^{s}\right) \hat{N}_{\theta}>0$ and is positively depending on $\theta$. Thus, Proposition 6 applies.

As another example, consider the case in which the workers' disutility of work is equal in both regions, but social security is less generous in region 1 , i.e. $w_{1}^{s}<w_{2}^{s}$. The lower unemployment benefits represents a negative location-specific spillover. However, with equal disutility of work, a lower $w^{s}$ translates into lower equilibrium wages, which represents a location-specific profit. For simplicity, we assume that $w_{1}-w_{2}=w_{1}^{s}-w_{2}^{s}$ which requires linearity in the labor argument in the utility function. Then, the labor cost in the bidding equilibrium is equal in both regions. Thus, differences in social security do not affect the bidding equilibrium described in Propositions 1 and 3 .

Corollary 4. Assume that $w_{1}^{s}<w_{2}^{s}$ and $w_{1}-w_{2}=w_{1}^{s}-w_{2}^{s}$. Then, Propositions 1 and 3 apply.

Thus, regions with lower wages and lower unemployment benefits are not more likely to attract the firm. ${ }^{16}$

\section{$5 \quad$ Simpler bidding strategies}

One may have doubts about the assumption that real world governments are willing or able to implement subtle mechanisms as the ones described above. Since we feel unable to make a final call on this question, we complement the analysis by considering simpler bidding strategies.

The probably simplest bidding strategy - regions offering unconditional upfront transfers - yields a straightforward equilibrium: The firm receives an offer equal to the sum of expected tax revenue, employment gains and spillovers. Firm types are thus pooled which benefits the low-profit and low-employment firms.

\footnotetext{
${ }^{16}$ This results may be seen in the light of the findings in Haufler and Mittermaier (2011) who show that countries with more unionized labor markets are more likely to win the bidding competition (although in a different model than ours).
} 
In the following, we will consider a slightly more complicated bidding strategy. We assume that regions can offer lump-sum payments $T$, tax breaks, $\tau \in[0, t]$, and employment subsidies, $\omega \in \mathbb{R}$, none of which can be made type-dependent. ${ }^{17} \mathrm{~A}$ bid has therefore the form of a triple $(T, \tau, \omega)$ and firm profits are $(1-t+\tau)\left(F_{\theta}\left(N_{\theta}\right)-w N_{\theta}\right)+\omega N_{\theta}+T$. Employment is then implied by $F_{\theta}^{\prime}\left(N_{\theta}\right)=w-\frac{\omega}{1-t+\tau}$.

Proposition 7. Assume that governments can only make type-dependent offers taking the form $(T, \tau, \omega)$. In equilibrium, regions have zero expected payoffs. The subsidy equals $\omega=(1-t+\tau) w^{s}$ and employment is efficient. The tax rebate $\tau$ is chosen as follows:

$$
\tau= \begin{cases}0 & \text { if } R_{h}-R_{l} \leq-t\left(\Pi_{h}^{*}-\Pi_{l}^{*}\right) \\ t+\frac{R_{h}-R_{l}}{\Pi_{h}^{*}-\Pi_{l}^{*}} & \text { if }-t\left(\Pi_{h}^{*}-\Pi_{l}^{*}\right)<R_{h}-R_{l}<0 \\ t & \text { if } R_{h}-R_{l} \geq 0\end{cases}
$$

The lump-sum payment $T$ is given by

$$
T=p_{l}\left((t-\tau) \Pi_{l}^{*}+R_{l}\right)+p_{h}\left((t-\tau) \Pi_{h}^{*}+R_{h}\right) .
$$

Proof: Any bidding equilibrium requires zero expected revenues for the government. Otherwise one region could increase its bid by $\epsilon$ and attract the firm with certainty. Similarly, any bidding equilibrium requires $\omega=(1-t+\tau) w^{s}$. Otherwise one region could set $\omega=(1-t+\tau) w^{s}$, thus maximizing the surplus, and reduce the lump-sum payment and increase its payoffs. Then, zero expected profits imply $T=p_{l}\left((t-\tau) \Pi_{l}^{*}+R_{l}\right)+$ $p_{h}\left((t-\tau) \Pi_{h}^{*}+R_{h}\right)$. Cross-subsidization occurs if $(t-\tau) \Pi_{l}^{*}+R_{l} \neq(t-\tau) \Pi_{h}^{*}+$ $R_{h}$. With $\omega$ fixed, $\tau$ and $T$ are chosen to minimize cross-subsidization. The region sets $\tau$ such that the difference is minimized which yields the rule in the Proposition.

The firm is better off when the regions' governments are not able to implement sophisticated mechanisms. This is stated in the following Corollary.

Corollary 5. Under symmetry, restricting the governments' sets of policy instruments to lump-sum payments, wage subsidies and tax rebates represents a Pareto improvement.

Proof: Under symmetry, the regions' payoffs are zero independent of the set of instruments. Since employment is at its first-best level with a

\footnotetext{
${ }^{17}$ Using the terminology from above, regions can make bids with linear type-independent conditions on both profits and employment.
} 
constrained set of instruments, the firm's profits are (weakly) larger in this setting.

\section{Discussion and conclusion}

This paper focusses on the role of incomplete information for the bidding behavior of regions. Incomplete information may explain some of the typical features of real-world bidding contests like (contractually fixed) performance targets on investment and employment. In plausible cases, these targets imply an inefficiently high level of employment. Our model may thus explain why sometimes (e.g. in the case of Nokia, see the Introduction) a firm may have an ex-post incentive to employ not as many workers as it originally agreed upon. More generally speaking, the overemployment result implies that both parties, the regional government and the firm, have an incentive to renegotiate the contract as the joint surplus can be increased. However, for these contracts to work as a separating device, renegotiations have to be (credibly) ruled out. Another implication is that, in some of the above analyzed cases, incomplete information actually benefits the regional governments. The reason is that, if the two competitors offer contracts with inefficiently high employment levels, the government that offers the less distortionary employment target (due to some asymmetry like location-specific profit) captures the efficiency gain. This highlights the role of information for the evaluation of interjurisdictional competition.

One important finding is that, in the absence of type-dependent spillovers, full tax rebate and a simple wage subsidy are sufficient to induce the firstbest allocation. The question arises why countries often use upfront payments instead of simple tax rebates. A potential answer is given by Bond and Samuelson (1986) who argue that governments may have better information on their regions profitability. Then, simply offering a tax rebate and an employment subsidy may not be enough to convince the firm that the location is of high quality. An upfront payment may act as a signal for the (expected) profits that the firm can earn in the region under consideration. ${ }^{18}$

Finally, the question may arise how the results would change if more than two regions compete for the firm. In the cases where the firm receives the full surplus (at least in expected terms), the properties of the equilibrium would

\footnotetext{
${ }^{18} \mathrm{~A}$ promising route for future research would be to allow for two-sided incomplete information (as pioneered in King and Welling, 1992). That is, the firm has some private information and the governments as well.
} 
not change since a third competitor cannot offer a better bid (as long as we abstract from asymmetries). However, in the cases in which asymmetries imply a non-zero gain for the regional governments, market entry would erode these gains if the entrants are more similar to the winning region.

\section{References}

Baldwin, R. and Okubo, T. (2009). Tax Reform, Delocation and Heterogeneous Firms, Scandinavian Journal of Economics 111(4): 741-764.

Baron, D.P. and Myerson, R.B. (1982). Regulating a monopolist with unknown costs, Econometrica 50: 911-930.

Becker, J. and Fuest, C. (2010). EU regional policy and tax competition, European Economic Review 54(1): 150-161.

Becker, J. and Fuest, C. (2011). Optimal Tax Policy when Firms Are Internationally Mobile, International Tax and Public Finance 18(5): 580-604.

Besley, T. and Seabright, P. (1999). The effects and policy implications of state aids to industry: an economic analysis, Economic Policy 14(28): 13-53.

Bierbrauer, F., Brett, C. and Weymark, J.A. (2013). Strategic nonlinear income tax competition with perfect labor mobility, Games and Economic Behavior 82: 292-311.

Biglaiser, G. and Mezzetti, C. (1993). Principals Competing for an Agent in the Presence of Adverse Selection and Moral Hazard, Journal of Economic Theory 61(2): 302-330.

Black, D. A. and Hoyt, W. H. (1989). Bidding for Firms, American Economic Review 79(5): 1249-1256.

Boadway, R., Cuff, K. and Marceau, N. (2002). Inter-Jurisdictional Competition for Firms, International Economic Review 43(3): 761-782.

Bond, E.W. and Samuelson, L. (1986). Tax Holidays as Signals, American Economic Review 76(4): 820-826. 
Chor, D. (2009). Subsidies for FDI: Implications from a Model with Heterogeneous Firms, Journal of International Economics 78(1): 113-125.

Dasgupta, P. and Maskin, E. (1986). The Existence of Equilibrium in Discontinuous Economic Games, II: Applications, Review of Economic Studies 53(1): $27-41$.

Davies, R. and Eckel, C. (2010). Tax Competition for Heterogeneous Firms with Endogenous Entry, American Economic Journal: Economic Policy 2(1): $77-102$.

Devereux, M.P. (2007). The Impact of Taxation on the Location of Capital, Firms and Profit: a Survey of Empirical Evidence, Oxford University Centre for Business Taxation Working Paper 07/02.

Feld, L. P. and Heckemeyer, J. H. (2011). FDI and Taxation: A Meta-study, Journal of Economic Surveys 25(2): 233-272.

Furusawa, T., Hori, K. and Wooton, I. (2010). A Race beyond the Bottom: The Nature of Bidding for a Firm, CESifo Working Paper No. 3049.

Haaparanta, P. (1996). Competition for Foreign Direct Investments, Journal of Public Economics 63(1): 141-153.

Haufler, A. and Mittermaier, F. (2011). Unionisation Triggers Tax Incentives to Attract Foreign Direct Investment, Economic Journal 121(553): 793818 .

Haufler, A. and Stähler, F. (2013). Tax Competition in a Simple Model with Heterogeneous Firms: How Larger Markets Reduce Profit Taxes, International Economic Review 54(2): 665-692.

Haufler, A. and Wooton, I. (1999). Country Size and Tax Competition for Foreign Direct Investment, Journal of Public Economics 71(1): 121-139.

Helpman, E., Melitz, M. J. and Yeaple, S. R. (2004). Export Versus FDI with Heterogenous Firms, American Economic Review 94(1): 300-316.

Martimort, D. and Stole, L. (2002). The Revelation and Delegation Principles in Common Agency Games, Econometrica 70: 1659-1673. 
Melitz, M. J. (2003). The Impact of Trade on Intra-Industry Reallocations and Aggregate Industry Productivity, Econometrica 71(6): 1695-1725.

King, I., McAfee, R. P. and Welling, L. (1993). Industrial Blackmail: Dynamic Tax Competition and Public Investment, Canadian Journal of Economics 26(3): 590-608.

King, I. and Welling, L. (1992). Commitment, Efficiency and Footloose Firms, Economica 59(233): 63-73.

Olsen, T. E. and Osmundsen, P. (2001). Strategic Tax Competition; Implications of National Ownership, Journal of Public Economics 81(2): 253-277.

Olsen, T. E. and Osmundsen, P. (2003). Spillovers and International Competition for Investments, Journal of International Economics 59(1): 211-238.

Osmundsen, P., Hagen, K. P. and Schjelderup, G. (1998). Internationally Mobile Firms and Tax Policy, Journal of International Economics 45(1): 97-113.

Riley, J. G. (1979). Informational Equilibrium, Econometrica 47(2): 331359 .

Rothschild, M. and Stiglitz, J. (1976). Equilibrium in Competitive Insurance Markets: An Essay on the Economics of Imperfect Information, Quarterly Journal of Economics 90(4): 629-649.

Scoones, D. and Wen, J.-F. (2001). Common and Private Values of the Firm in Tax Competition, Journal of Public Economic Theory 3(4): 373-389.

Wilson, C. (1977). A Model of Insurance Markets with Incomplete Information, Journal of Economic Theory 16(2): 167-207.

Zodrow, G. R. (2010). Capital Mobility and Capital Tax Competition, National Tax Journal 63(4): 865-901. 